\title{
Prevalence of retinopathy in Caucasian type 2 diabetic patients from the South of Brazil and relationship with clinical and metabolic factors
}

\section{K.G. Santos ${ }^{1}$, B. Tschiedel ${ }^{2}$, \\ J.R. Schneider ${ }^{3}$, \\ K.E.P. Souto ${ }^{2}$ \\ and I. Roisenberg ${ }^{1}$}

\author{
${ }^{1}$ Departamento de Genética, Universidade Federal do Rio Grande do Sul, \\ Porto Alegre, RS, Brasil \\ Serviços de ${ }^{2}$ Endocrinologia and ${ }^{3}$ Oftalmologia, Grupo Hospitalar Conceição, \\ Porto Alegre, RS, Brasil
}

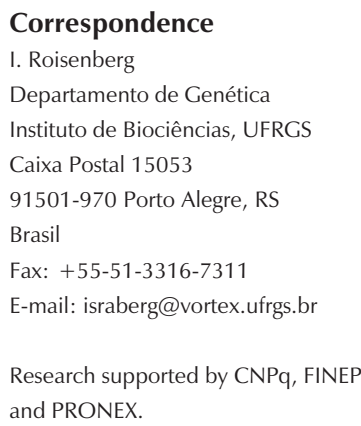

Received November 18, 2003 Accepted October 13, 2004

\begin{abstract}
Diabetic retinopathy (DR) is a sight-threatening chronic complication of diabetes mellitus and is the leading cause of acquired blindness in adults. In this cross-sectional study, we investigated the prevalence of and the factors associated with DR in an analysis of 210 consecutive and unrelated Brazilian Caucasians with type 2 diabetes mellitus. Retinopathy was evaluated by ophthalmoscopy and/or biomicroscopy through dilated pupils. The relationship between clinical and metabolic variables and the presence of DR was assessed by logistic regression analysis. DR was detected in 99 of the 210 patients (47\%). In the univariate logistic regression analyses, male sex, duration of diabetes, body mass index, glycated hemoglobin, C-peptide, LDL cholesterol, smoking, and albumin excretion rate were found to be associated with the presence of DR. However, the multiple logistic regression analysis showed that only duration of diabetes (odds ratio $(\mathrm{OR})=1.15,95 \% \mathrm{CI}=1.09-1.22 ; \mathrm{P}<0.001)$, glycated hemoglobin $(\mathrm{OR}=1.21,95 \% \mathrm{CI}=1.01-1.46 ; \mathrm{P}=0.047)$ and albumin excretion rate $>100 \mu \mathrm{g} / \mathrm{min}(\mathrm{OR}=12.72,95 \% \mathrm{CI}=3.89-41.56 ; \mathrm{P}<0.001)$ were independently associated with DR. Although DR was found to be frequent among Brazilian type 2 diabetic patients, its prevalence was within the range observed in other Caucasian populations. Our findings emphasize the need for good glycemic control in order to prevent or delay the onset of DR, since the most well-known risk factors for the development of this complication in type 2 diabetes mellitus, such as duration of diabetes, glycated hemoglobin and albumin excretion rate were independently related to DR.
\end{abstract}

Diabetic retinopathy (DR) is a sight-threatening chronic complication of diabetes mellitus (DM) and is the leading cause of acquired blindness in adults, as reported by the American Diabetes Association (1). Up to
Key words

- Diabetic retinopathy

- Type 2 diabetes mellitus

- Risk factors

- Caucasian subjects 
sure $(3,4)$, and increased albumin excretion rate (AER) $(5,6)$ have been identified as important risk factors for the onset and progression of DR in type 2 DM. However, epidemiological studies investigating the occurrence of DR in Brazilian type 2 diabetic patients are limited to the Southeast region (7).

The aim of the present study was to assess the prevalence of and the clinical and metabolic factors associated with DR in Caucasians with type $2 \mathrm{DM}$, from the State of Rio Grande do Sul in the South of Brazil.

A cross-sectional study was carried out on type 2 diabetic patients regularly attending the diabetes outpatient clinics at the Endocrinology Service of the Grupo Hospitalar Conceição, in Porto Alegre, located in the southernmost Brazilian State. Diagnosis of type $2 \mathrm{DM}$ was based on the criteria of the American Diabetes Association (8). All patients with type $2 \mathrm{DM}$ were invited to participate in a study investigating clinical and metabolic risk factors for diabetic complications. The present study refers to the analysis of 210 consecutive and unrelated patients (142 females and 68 males; mean age $58.7 \pm$ 12.0; age range 28 to 87 years; mean duration of diabetes $10.5 \pm 9.7$ years) of European ancestry (mainly from Italy, Germany, Portugal, and Spain). All patients were born in Rio Grande do Sul, $89 \%$ lived in the metropolitan area of Porto Alegre and 11\% in the rural area. Subjects from other ethnic groups were not included in the present study. The patients answered a standard questionnaire on clinical history and personal habits. The study protocol was approved by the Grupo Hospitalar Conceição Ethics Committee and all patients gave written informed consent to participate.

Hypertension was defined as systolic blood pressure $\geq 140 \mathrm{mmHg}$ and/or diastolic blood pressure $\geq 90 \mathrm{mmHg}$, or was considered to be present if the patient was on treatment with antihypertensive drugs (9). Smoking was classified as "yes/no" (current and former smokers as opposed to subjects who had never smoked), and insulin therapy was defined as "yes/no" for regular use of insulin with or without oral hypoglycemic agents as compared to subjects who did not use insulin.

DR was assessed by ophthalmoscopy and/ or biomicroscopy through the dilated pupils by a physician specialized in retina (1), who had no knowledge of the patients' characteristics, and fluorescein angiography was obtained when indicated. DR was graded as absent, minimal, moderate, or severe retinopathy, as published elsewhere (10). For the purpose of the present study, the comparisons between the groups of patients were performed according to the presence or absence of DR, regardless of its levels of severity.

Fasting venous blood samples were obtained for the determination of glycated hemoglobin $\left(\mathrm{HbA}_{1}\right)$, creatinine, $\mathrm{C}$-peptide, and plasma lipids. Twenty-four-hour urine samples were collected from 187 patients on at least two occasions for the measurement of AER. Glycated hemoglobin was measured by a colorimetric method (Labtest Diagnostica S.A., Lagoa Santa, MG, Brazil; laboratory reference range: 5.4-8.2\%). Plasma creatinine concentrations were determined by a modified Jaffé reaction using an automated analyzer (Dade Behring Inc., Newark, NJ, USA). C-peptide levels were measured by radioimmunoassay (intra-assay coefficient of variation $(\mathrm{CV})<10 \%$ and interassay CV $<9 \%$; Diagnostic System Laboratories Incorporation, Webster, TX, USA). Total plasma cholesterol, HDL cholesterol and triglycerides were measured by enzymatic methods using an automated analyzer (Dade Behring Inc.). LDL cholesterol was calculated using Friedewald's formula (LDL $=$ total cholesterol $-\mathrm{HDL}-\mathrm{TG} / 5)$. Urinary albumin was determined with a double antibody radioimmunoassay (intra-assay $\mathrm{CV}$ $<5 \%$ and interassay $\mathrm{CV}<3.5 \%$; Diagnostic Products Corporation, Los Angeles, CA, USA). 
Statistical analyses were performed using the SPSS package (SPSS for Windows, Version 8.0). Comparisons between groups were made using the unpaired Student $t$-test or the Mann-Whitney U-test. The $\chi^{2}$ test was used to compare categorical characteristics between groups of subjects. A P value $<0.05$ was considered to be statistically significant. Logistic regression analyses were performed to assess the factors associated with the presence of DR as well as to control confounding factors.

Table 1 shows the clinical and metabolic characteristics of the patients regarding DR. Of the 99 patients with DR (which corresponds to $47.1 \%$ of the 210 patients analyzed), 36 (36.4\%) had severe DR. The patients with DR had higher $\mathrm{HbA}_{1}$ and LDL cholesterol levels, as well as a higher frequency of smoking. Their insulinopenia was more severe (lower C-peptide levels and more frequent use of insulin for diabetes treatment), and they were leaner than subjects without this complication. There was a trend toward a higher frequency of DR in men than in women (57 vs 42\%, $\mathrm{P}=0.057$; $\chi^{2}$ test with the Yates correction). The patients with DR had a longer duration of diabetes than those without it. In fact, the prevalence of DR increased from $17 \%$ at 5 years of duration of diabetes to $73 \%$ after 15 years of diabetes. Moreover, an AER > 100 $\mu \mathrm{g} / \mathrm{min}$ was much more frequent among the patients with retinopathy than among those without it $(38 v s 5 \%, \mathrm{P}<0.001)$.

The multiple regression analysis model was constructed using the factors significantly associated with the presence of retinopathy in the univariate analyses, i.e., male sex $(P=0.047)$, duration of diabetes $(P<$ $0.001)$, body mass index $(\mathrm{P}=0.030), \mathrm{HbA}_{1}$ $(\mathrm{P}=0.012), \mathrm{C}$-peptide $(\mathrm{P}=0.015), \mathrm{LDL}$ cholesterol $>3.59 \mathrm{mmol} / \mathrm{l}(\mathrm{P}=0.026)$, smoking $(\mathrm{P}=0.033)$, and AER $(\mathrm{P}<0.001$, for patients with AER $>100 \mu \mathrm{g} / \mathrm{min}$ as compared to those with AER $<20 \mu \mathrm{g} / \mathrm{min}$ ).

The factors that remained statistically and independently associated with DR in the multiple logistic analysis after adjustment for sex and age were duration of diabetes, $\mathrm{HbA}_{1}$ levels and AER, as shown in Table 2. Interaction effects among the variables were not significant.

DR was very frequent in our cross-sectional study. Yet its prevalence was somewhat higher than that observed in Caucasians with type $2 \mathrm{DM}$ from the United States (39\%) and from South Africa $(41 \%)(11,12)$, and lower than that found in Caucasians from New Zealand (60\%) (13). Most pa-

Table 1. Clinical and laboratory characteristics of patients with type II diabetes mellitus with and without diabetic retinopathy.

\begin{tabular}{|c|c|c|c|}
\hline Variable & Without retinopathy & With retinopathy & $\mathrm{P}$ \\
\hline Number (male/female) & $111(29 / 82)$ & $99(39 / 60)$ & 0.057 \\
\hline Age (years) & $57.5 \pm 13.1$ & $59.9 \pm 10.6$ & \\
\hline Duration of diabetes (years) & $6.6 \pm 7.5$ & $14.9 \pm 10.1$ & $<0.001$ \\
\hline Glycated hemoglobin (\%) & $9.8 \pm 2.3$ & $10.6 \pm 2.2$ & 0.010 \\
\hline Smoking (\%) & 28.8 & 43.4 & 0.039 \\
\hline Hypertension (\%) & 59.5 & 68.7 & \\
\hline Systolic blood pressure $(\mathrm{mmHg})$ & $136 \pm 19$ & $137 \pm 23$ & \\
\hline Diastolic blood pressure $(\mathrm{mmHg})$ & $85 \pm 10$ & $84 \pm 10$ & \\
\hline Body mass index $\left(\mathrm{kg} / \mathrm{m}^{2}\right)$ & $30.7 \pm 6.2$ & $28.9 \pm 4.0$ & 0.016 \\
\hline Creatinine $(\mu \mathrm{mol} / \mathrm{l})$ & $77 \pm 24$ & $90 \pm 39$ & 0.002 \\
\hline C-peptide (nmol/l) & $1.07 \pm 0.68$ & $0.76 \pm 0.58$ & 0.006 \\
\hline Insulin therapy (\%) & 21.6 & 51.5 & $<0.001$ \\
\hline Total cholesterol (mmol/l) & $5.54 \pm 1.12$ & $5.91 \pm 1.43$ & 0.050 \\
\hline HDL cholesterol (mmol/l) & $1.19 \pm 0.60$ & $1.06 \pm 0.28$ & \\
\hline LDL cholesterol (mmol/l) & $3.54 \pm 1.05$ & $3.99 \pm 1.30$ & 0.014 \\
\hline Triglycerides (mmol/l) & $1.55(0.29-16.59)$ & $1.56(0.41-16.24)$ & \\
\hline AER $>100 \mu \mathrm{g} / \mathrm{min}(\%)$ & 4.9 & 38.1 & $<0.001$ \\
\hline
\end{tabular}

Data are reported as mean \pm SD or as $\%$. Triglyceride values are reported as median and range. The groups were compared by the unpaired Student $t$-test, the MannWhitney U-test or the $\chi^{2}$ test.

Table 2. Relationships between various clinical factors and the presence of diabetic retinopathy

\begin{tabular}{lrrr}
\hline Variable & OR & $95 \% \mathrm{Cl}$ & $\mathrm{P}$ \\
\hline Male sex & 1.40 & $(0.56-3.49)$ & \\
Age (years) & 0.98 & $(0.94-1.02)$ & \\
Duration of diabetes (years) & 1.15 & $(1.09-1.22)$ & $<0.001$ \\
Glycated hemoglobin (\%) & 1.21 & $(1.01-1.46)$ & 0.047 \\
AER $>100 \mu \mathrm{g} / \mathrm{min}^{*}$ & 12.72 & $(3.89-41.56)$ & $<0.001$ \\
\hline
\end{tabular}

$\mathrm{OR}=$ odds ratio $; 95 \% \mathrm{Cl}=95 \%$ confidence interval; $\mathrm{AER}=$ albumin excretion rate ${ }^{*} \mathrm{P}<0.001$ compared to patients with $\mathrm{AER}<20 \mu \mathrm{g} / \mathrm{min}$ (logistic regression analysis). 
tients had never been examined in order to assess retinopathy and many of them were not aware of the risk of visual dysfunction.

Duration of diabetes and hyperglycemia are two well-known risk factors for the development of DR (1-3,6,7,14-17). In our study, patients with retinopathy had a longer duration of diabetes and more severe diabetes than patients without it, as indicated by a lower body mass index, a higher frequency of insulin therapy, higher $\mathrm{HbA}_{1}$ levels, lower C-peptide levels, and a higher AER. Since these metabolic factors, which have been shown to be individually related to retinopathy, are correlated with one another and reflect poor metabolic control, only glycated hemoglobin, duration of diabetes and AER remained independently associated with the presence of retinopathy in the final analysis.

Both proteinuria and macroalbuminuria have been related to the development of DR in type $2 \mathrm{DM}(5,6,18)$. In the present study, an AER $>100 \mu \mathrm{g} / \mathrm{min}$ was strongly associated with the presence of DR, providing further evidence that once a complication has been established, glycemic control can be fundamental in delaying or avoiding the onset of other complications.

Although the clinical trial conducted by the UK Prospective Diabetes Study Group $(3,4)$ and the Hoorn study $(16)$ have shown that hypertension is a serious risk factor for the onset and the progression of DR in type 2 $\mathrm{DM}$, other studies have found no relation- ship between this complication and high blood pressure $(15,17,19)$, as was also the case in the present study. Even if hypertension were associated with retinopathy, we would not find this association, because the two groups of patients (with and without retinopathy) presented similar mean levels of systolic and diastolic blood pressure that could be attributed to the treatment with antihypertensive drugs, since $54.1 \%$ of the patients without retinopathy use some medication to control blood pressure versus $54.6 \%$ of the patients with retinopathy.

DR was present in approximately half of the patients with type $2 \mathrm{DM}$. This high frequency emphasizes the need to screen patients with type $2 \mathrm{DM}$ for the detection of DR in the diagnosis of diabetes. However, the frequency of this complication may be restricted to the patients studied in the present investigation and cannot be extended to all diabetic patients. To our knowledge, this is the first study reporting on the prevalence of and the factors associated with DR in type 2 diabetic patients, in the South of Brazil. Moreover, our findings contribute to emphasize the need for good glycemic control in order to prevent or delay the onset of DR, since duration of diabetes, glycated hemoglobin and AER were independently related to DR. In conclusion, DR is a serious diabetic complication and public health strategies are required in order to reduce its risk factors and decrease its prevalence.

\section{References}

1. Fong DS, Aiello L, Gardner TW, King GL, Blankenship G, Cavallerano JD, Ferris III FL \& Klein R (2003). Diabetic retinopathy. Diabetes Care, 26 (Suppl I): S-99-S-102.

2. UK Prospective Diabetes Study Group (1998). Intensive blood-glucose control with sulphonylureas or insulin compared with conventional treatment and risk of complications in patients with type 2 diabetes (UKPDS 33). Lancet, 352: 837-853.

3. Stratton IM, Kohner EM, Aldington SJ, Turner RC, Holman RR, Manley SE \& Matthews DR (2001). UKPDS 50: risk factors for incidence and progression of retinopathy in type II diabetes over 6 years from diagnosis. Diabetologia, 44: 156-163.

4. UK Prospective Diabetes Study Group (1998). Tight blood pressure control and risk of macrovascular and microvascular complications in type 2 diabetes: UKPDS 38. British Medical Journal, 317: 703713.

5. Lunetta M, Infantone L, Calogero AE \& Infantone $E$ (1998). Increased urinary albumin excretion is a marker of risk for retinopathy and coronary heart disease in patients with type 2 diabetes mellitus. Diabetes Research and Clinical Practice, 40: 45-51.

6. Liu DP, Molyneaux L, Chua E, Wang YZ, Wu CR, Jing H, Hu LN, Liu YJ, Xu ZR \& Yue DK (2002). Retinopathy in a Chinese population with type 2 diabetes: factors affecting the presence of this complication at diagnosis of diabetes. Diabetes Research and Clinical Practice, 56: 125-131. 
7. Foss MC, Paccola GMGF, Souza V \& lazigi N (1989). Analytic study of type 2 diabetic patients in a population sample from Ribeirão Preto area (São Paulo). Revista da Associação Médica Brasileira, 35: 179-183.

8. The Expert Committee on the Diagnosis and Classification of Diabetes Mellitus (2000). Report of the expert committee on the diagnosis and classification of diabetes mellitus. Diabetes Care, 23 (Suppl I): S-4-S-19.

9. Anonymous (1997). The sixth report of the Joint National Committee on prevention, detection, evaluation, and treatment of high blood pressure. Archives of Internal Medicine, 157: 2413-2446.

10. Leske MC, Wu SY, Hyman L, Li X, Hennis A, Connell MAS \& Schachat AP (1999). Diabetic retinopathy in a black population: the Barbados Eye Study. Ophthalmology, 106: 1893-1899.

11. Klein R, Klein BEK, Moss SE, Davis MD \& DeMets DL (1989). The Wisconsin Epidemiologic Study of Diabetic Retinopathy X: four-year incidence and progression of diabetic retinopathy when age at diagnosis is 30 years or more. Archives of Ophthalmology, 107: 244-249.

12. Kalk WJ, Joannou J, Ntsepo S, Mahomed I, Mahanlal P \& Becker PJ (1997). Ethnic differences in the clinical and laboratory associations with retinopathy in adult onset diabetes: studies in patients of African, European and Indian origins. Journal of Internal Medicine, 241: 31-37.

13. Florkowski CM, Scott RS, Moir CL \& Graham PJ (1998). Clinical and biochemical outcomes of type 2 diabetes mellitus in Canterbury, New Zealand: a 6-year cohort study. Diabetes Research and Clinical Practice, 40: 167-173.

14. Kim HK, Kim CH, Kim SW, Park JY, Hong SK, Yoon YH \& Lee KU (1998). Development and progression of diabetic retinopathy in Koreans with NIDDM. Diabetes Care, 21: 134-138.

15. West SK, Klein R, Rodriguez J, Muñoz B, Broman AT, Sanchez R \& Snyder R (2001). Diabetes and diabetic retinopathy in a MexicanAmerican population: proyecto VER. Diabetes Care, 24: 1204-1209.

16. van Leiden HA, Dekker JM, Moll AC, Nijpels G, Heine RJ, Bouter LM, Stehouwer CD \& Polak BC (2002). Blood pressure, lipids, and obesity are associated with retinopathy: the Hoorn study. Diabetes Care, 25: 1320-1325.

17. Yoshida Y, Hagura R, Hara Y, Sugasawa G \& Akanuma Y (2001). Risk factors for the development of diabetic retinopathy in Japanese type 2 diabetic patients. Diabetes Research and Clinical Practice, 51: 195-203.

18. Savage S, Estacio RO, Jeffers B \& Schrier RW (1996). Urinary albumin excretion as a predictor of diabetic retinopathy, neuropathy, and cardiovascular disease in NIDDM. Diabetes Care, 19: 1243-1248.

19. Klein R, Klein BEK, Moss SE, Davis MD \& DeMets DL (1989). Is blood pressure a predictor of the incidence or progression of diabetic retinopathy? Archives of Internal Medicine, 149: 2427-2432. 